\title{
Detection of pathogenic Staphylococcus aureus bacteria by Electrochemical Impedance
}

\author{
M. Braiek ${ }^{1,2}, \underline{\text { K. Bekir Rokbani }} i^{3}$, B. Mrabet ${ }^{3}$, A. Bakhrouf ${ }^{3}$, A. Maaref ${ }^{1}$, and N. Jaffrezic-Renault ${ }^{2}$ \\ ${ }^{1}$ Laboratoire de Physique et Chimie des Interfaces, Faculté des Sciences de Monastir, Tunisie, \\ Avenue de l'Environnement, 5019 Monastir, Tunisia \\ ${ }^{2}$ Laboratoire des Sciences Analytiques, UMR CNRS 5180, Université Claude Bernard-Lyon1, \\ Batiment CPE, 69622 Villeurbanne Cedex, France \\ Mohamed_braiek@yahoo.fr \\ ${ }^{3}$ Laboratoire d'Analyse, Traitement et Valorisation des Polluants de l'Environnement et des Produits. \\ Faculté de Pharmacie de Monastir, Tunisia
}

\begin{abstract}
The timely detection of pathogens is a subject of great importance. In this work, the objective is to elaborate an immunosensing system for detection and quantification of Staphylococcus aureus. Poyclonal anti-S. aureus are immobilized onto gold electrodes via chemical bond formation between antibody amino groups and a carboxylic acid containing self-assembled molecular monolayer. The evaluation of the developed immunosensor performance was accomplished through the monitoring of the electron-transfer resistance detected by electrochemical impedance spectroscopy in the presence of $\left[\mathrm{Fe}(\mathrm{CN})_{6}{ }^{3}\right] /\left[\mathrm{Fe}(\mathrm{CN})_{6}{ }^{4}\right]$ as redox probe. A low detection limit of $10 \mathrm{fcu} / \mathrm{ml}$ and a linear range up to $10^{7}$ $\mathrm{cfu} / \mathrm{ml}$ were obtained.
\end{abstract}

Key words: Staphylococcus aureus, self-assembled molecular monolayer, immunosensor, electrochemical impedance spectroscopy.

\section{Introduction}

The detection of pathogenic bacteria remains a challenging and important issue for ensuring food safety and security, for controlling water and soil pollution, and for preventing bioterrorism and nosocomial diseases [1]. In France the bacterial pathogen Staphylococcus aureus is the second major cause of food poisoning outbreaks after Salmonella [2].

Biosensors techniques are particularly attractive for the detection and identification of pathogenic microorganisms due to their potential sensitivity and specificity [3]. Several detection techniques have been employed for identification and /or monitoring of bacterial contamination in food. Electrochemical impedance spectroscopy (EIS) continues to be a topic of recent interest $[1,4,5]$. On the other hand, the immobilization of biomolecules on transducers is a potentially important prerequisite for the fabrication of immunosensor. Various recent works have focused on self-assembled monolayers (SAMs) thanks to its simplicity, versatility, reproducibility and high level of molecular ordering in the electrode modification [6]. In fact Alkanethiols terminated with functional groups, such as a carboxylic acid and amine, are strongly chemisorbed with high order on various metal surfaces such as gold.

\section{Experimental}

\section{1- Reagents}

Polyclonal antibodies (developed in rabbit) against Staphylococcus aureus were obtained from BIOtech ${ }^{\text {RDP }}$ (Sfaxe, Tunisia).

16-Mercaptohexadecanoic acid, N-(3 Dimethylaminopropyl)-N'-ethylcarbodiimide hydrochloride (EDC), N-hydroxysuccinimide (NHS), potassium Ferrocyanide $\left(\mathrm{K}_{4} \mathrm{Fe}(\mathrm{CN})_{6}\right)$, potassium ferricyanid $\left(\mathrm{K}_{3} \mathrm{Fe}(\mathrm{CN})_{6}\right)$, Phosphate Buffered Saline (PBS), ethanolamine, 30\% hydrogen peroxide (all from Sigma), hydrochloric acid (Prolabo), and Ethanol was obtained from Fluka (purity $>99 \%$ ). All solutions were prepared with deionized Milli-Q water.

\section{2- Bacterial Culture}

S. aureus (ATCC25923) cells were grown in tryptic soy broth [TSB, (Difco)] or on TSB agar plates. High titer of bacteria suspension was prepared as follows: liquid culture mediums were inoculated by $100 \mu \mathrm{L}$ of preculture solution and cultivated at $37^{\circ} \mathrm{C}$ for $18-24 \mathrm{~h}$. Centrifuge the cells at $6400 \mathrm{rpm}$ for $5 \mathrm{~min}$, wash the cells 
twice, and resuspend the cells in sterile phosphate-buffered saline (PBS). Determine the viable cells and bacterial concentration with spread-plate technique. The optical density OD of the bacterial culture has been measured for the determination of bacterial growth stationary phase.

\section{3- Instrumentation}

Electrochemical measurements were performed with a three-electrode cell, comprising of a saturated calomel electrode (SCE) as the reference electrode, a platinum plate as auxiliary electrodes and functionalized gold substrate act as working electrodes.

Cyclic voltammetry (CV) and impedance measurements were carried out with a Potentiostat/galvanostat Radiometer Analytical (Voltalab40-PGZ301).

\section{4- Procedure}

The Au electrodes were ultrasonically cleaned by acetone and $5 \mathrm{~min}$ in a mixture piranha $\left(\mathrm{H}_{2} \mathrm{O}_{2} / \mathrm{HCl}: 3 / 7\right)$, between and after these treatments, the gold electrodes were rinsed thoroughly with ultrapure water, then rinsed with absolute ethanol and dried in a flow of nitrogen. After cleaning, gold substrates were immersed into a thiol solution (10mM) dissolved in ethanol for $12 \mathrm{~h}$. The SAMs layer of thiols was activated by incubation in a mixture of $0.1 \mathrm{M}$ EDC and $0.1 \mathrm{M}$ NHS for $1 \mathrm{~h}$. After that, the incubation of Polyclonal antibodies against $S$. aureus (ATCC 25923) suspension in PBS at $0.2 \mathrm{mg} / \mathrm{ml}$ for $1 \mathrm{~h}$, the inbound NHS esters were blocked by flowing ethanolamine $10 \mathrm{mM}$ for $20 \mathrm{~min}$ (figure1).

In order to detect $S$. aureus by direct essay, the prepared surface sensor was incubated in different concentration of $S$. aureus (10 to $10^{9}$ $\mathrm{CFU} / \mathrm{ml})$. After each incubation, impedance measurement was effected to check sensitivity of immunosensor elaborated.

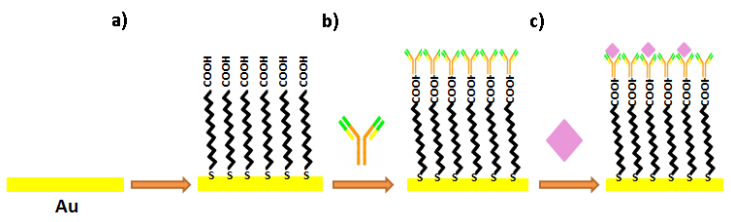

Fig. 1. Structure and components of the immunosensor: a) self-assembled monolayers b) antibody binding and c) the detection o bacteria.

\section{Results and discussion}

A carboxylic acid derivative was self-assembled on the electrode surface and activated by reaction with a carbodiimide. Subsequently, the in antibody was attached covalently to the surface via amide bonding [6].

The quality of self-assembled monolayers formed onto electrode surfaces and the antibody binding were investigated by cyclic voltammetry and impedance spectroscopy in the presence of the redox probe Ferrocyanide. Figure 2 show how the electric current through the electrode is effectively reduced in the presence of the monolayers

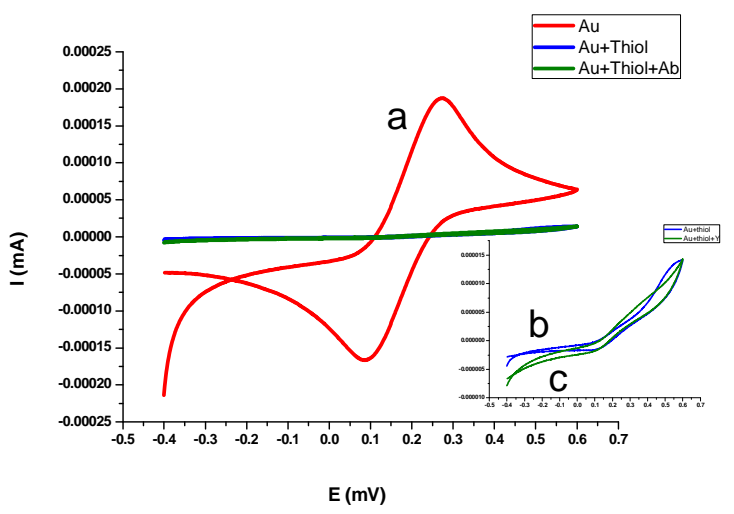

Fig. 2. Cyclic voltammograms recorded in the presence of $\left[\mathrm{Fe}(\mathrm{CN})_{6}{ }^{3-}\right] /\left[\mathrm{Fe}(\mathrm{CN})_{6}{ }^{4-}\right]$ as redox probe at scan rates of $100 \mathrm{mV} / \mathrm{s}$, a) bare Au b) gold electrode modifided with a SAMs and c) $b+$ covalently bonded antibody.

Nyquist plots of impedance spectra obtained for the different fictionalization steps show a remarkable variation of the charge transfer resistance $R_{C T}$ (figure3), in fact, the electron transfer resistance of redox probe increased in large value after SAM modification and immobilization of Anti-S. aureus antibody.

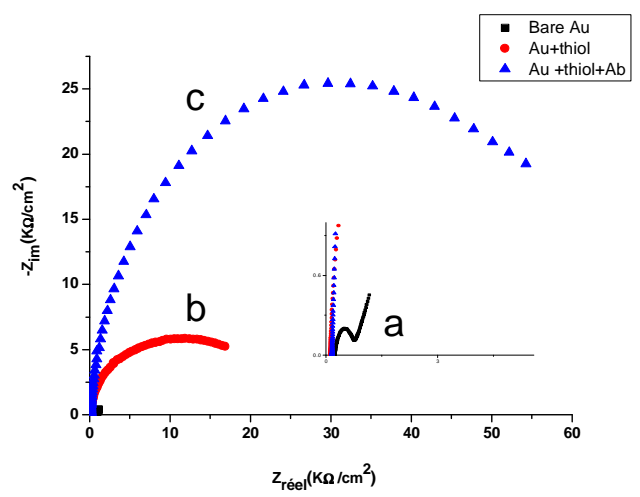

Fig. 3. Nyquist plots of impedance spectra's recorded in the presence of $\left[\mathrm{Fe}(\mathrm{CN})_{6}^{3-}\right] /\left[\mathrm{Fe}(\mathrm{CN})_{6}^{4-}\right]$ as redox probe at a frequency range between $0.1 \mathrm{~Hz}$ and $100 \mathrm{KHz}$, a) bare $\mathrm{Au}$ b) gold electrode modifided with a SAMs and c) b + covalently bonded antibody.

Nyquist diagram for the faradic impedance measurement of modified gold electrode in the presence of varying concentration of target bacteria is given in figure $4(A)$, the most 
distinctive differences in magnitude of impedance were observed at the low frequency.

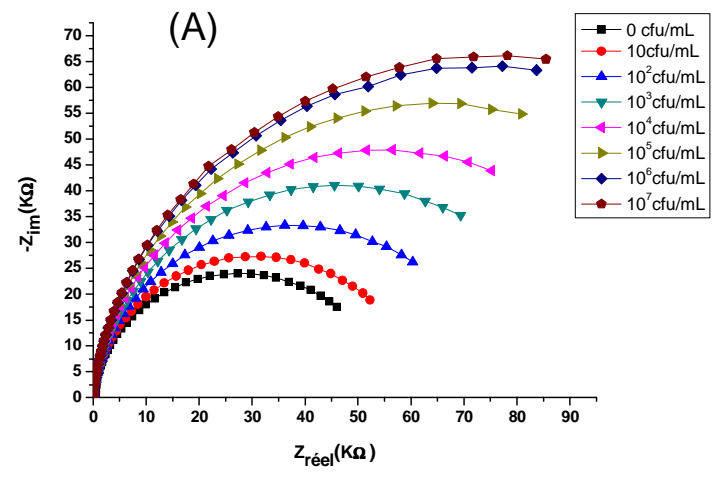

(B)

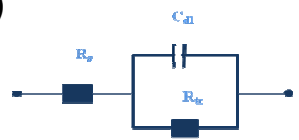

Fig. 4. (A) Nyquist plots of impedance spectra's obtained for increasing concentrations of $S$. aureus (ATCC25923) from 10 to $10^{7} \mathrm{cfu} / \mathrm{ml}$ in PBS and $\mathrm{Fe}\left(\mathrm{CN}_{6}\right)$. (B) Equivalent electrical circuit used to the fit the impedance spectra.

The data of electrochemical impedance measurements can be fitted perfectly using the software Zplot/Zview. The equivalent circuit consists of the ohmic resistance $\left(R_{s}\right)$, the charge transfer resistance $\left(\mathrm{R}_{\mathrm{CT}}\right)$ and the constant phase element (CPE), figure $4(\mathrm{~B})$. $A$ linear relationship between the polarization resistance and decimal logarithmic value of $S$. aureus concentrations was found ranging from 10 to $10^{7} \mathrm{CFU} / \mathrm{mL}$, with a slope of 14.66 and a correlation coefficient of 0.994 (figure 5).

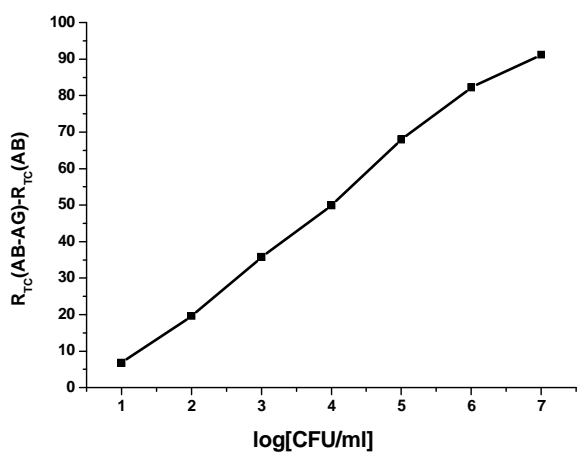

Fig. 5. Variation of the charge transfer resistance RTC with the logarithmic concentration of S. aureus from 10 to $10^{7} \mathrm{cfu} / \mathrm{ml}$. Values are normalized to $R_{C T}$ in absence of bacteria detection, the datafollow a sigmoidal curve (fitr $\left.{ }^{2}=0.994\right)$.

\section{Conclusion}

A simple and highly sensitive impedance based immunosensor was developed for detection of $S$. aureus bacteria. In fact, this work has demonstrated that the 16Mercaptohexadecanoic acid, with a long alkyl chain and function group of carboxylic acid, has been successfuly deposited on the gold electrode, enabling the subsequent immobilisation of anti-S. aureus.

\section{References}

\section{References}

[1] R. Maalouf, Ch. Fournier-Wirth, J. Coste, H. Chebib, Y. Saikali, O. Vittori, A. Errachid, J. Cloarec, C. Martelet and N. Jaffrezic-Renault, Anal Chem, 79, 4879-4886 (2007), DOI 10.1021/ac070085n

[2] S. Boujday, R. Briandet, M. Salmain, J. Herry, P. Marnet, M. Gautier, C. Pradier, Microchim Acta, 163:203-209 (2008), DOI 10.1007/s0

[3] Ed. M. Zoutrob, S. Elwary, A. Turner, Springer Science+Business Media, LLC, New York, (2008)

[4] V. Escamilla-Gomez, S. Campuzano, M. Pedro, J. M. Pingarron, Biosensors and Bioelectronics, 24, 3365-3371 (2009), DOI 10.1016/j.bios.2009.04.047

[5] C. Joung, H.-Nah Kim, H. Im, H.-Yeong Kim, M.Haw Oh, Y.-Rok Kim, Sensor and Actuators B, DOI 10.1016/j.snb.2011.11.041

[6] M. Barreiros dos Santos, C. Sporer, N. Sanvicens, N. Pascual, A. Errachid, E. Martinez, M. Marco, V. Teixeira, J. Samiter, Procedia Chemistry, 1, 1291-1294, (2009) 